
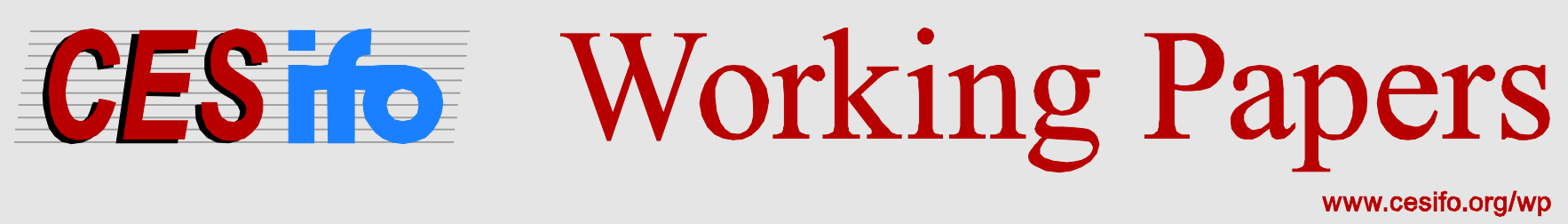

\title{
Destination vs. Origin-based Commodity Taxation in Large Open Economies with Unemployment
}

\author{
Fabio Antoniou \\ Panos Hatzipanayotou \\ Nikos Tsakiris
}

CESIFO WORKING PAPER NO. 5585

CATEGORY 1: PuBliC FinANCE

OCTOBER 2015

An electronic version of the paper may be downloaded

- from the SSRN website:

- from the RePEc website:

- from the CESifo website:

www.SSRN.com

www.RePEc.org

www.CESifo-group.org/wp 


\title{
Destination vs. Origin-based Commodity Taxation in Large Open Economies with Unemployment
}

\begin{abstract}
We construct a perfectly competitive general equilibrium model of two large and symmetric countries producing tradable commodities and a public consumption good. Destination or origin-based taxes are levied on the consumption of the tradable goods. In both countries, an institutional minimum wage leads to involuntary unemployment. We derive the Nash equilibrium consumption taxes under the two taxation principles and compare them to their cooperative rates and to their rates when countries are small. We demonstrate that terms of trade effects are absent in destination-based taxation, but they exist under origin-based taxation. Both taxation principles lead to ambiguous employment externalities. Nash equilibrium destinationbased taxes are inefficiently low when the exporting sector in each country is non-labor intensive. The Nash equilibrium origin-based taxes can either be higher or lower that the corresponding cooperative rates.
\end{abstract}

JEL-Codes: F160, H210, H870.

Keywords: Nash vs. cooperative destination and origin based consumption taxes, terms of trade effects, minimum wage and unemployment.

\author{
Fabio Antoniou \\ Department of Economics \\ University of Ioannina \\ P.O. Box 1186 \\ Greece - 45110 Ioannina \\ fantoniou@cc.uoi.gr
}

\author{
Panos Hatzipanayotou* \\ Department of International and European \\ Economic Studies / Athens University of \\ Economics and Business \\ 76, Patission str. \\ Greece - Athens 10434 \\ hatzip@aueb.gr
}

\author{
Nikos Tsakiris \\ Department of Economics \\ University of Ioannina \\ P.O. Box 1186 \\ Greece - 45110 Ioannina \\ ntsak@cc.uoi.gr
}

*corresponding author

October 2015

We thank A. Razin, C. Kotsogiannis, A. Philippopoulos, G. Economides, C. Wittneben, participants in the International Conference on Public Policy and Public Sector Reforms, Delphi-Greece 2015, and in the 71st Annual IIPF Congress, for constructive comments and suggestions. Any remaining errors solely burden the authors. The authors graciously acknowledge the funding of this research by the Research Centre of Athens University of Economics and Business, in the framework of the project "Original Scientific Publications". 


\section{Destination vs. Origin-based Commodity Taxation in Large Open Economies with Unemployment}

\section{Introduction}

A key question in the international commodity taxation literature is whether destination-based or origin-based commodity taxation leads to a socially efficient outcome when countries set taxes non-cooperatively. Numerous arguments have been analyzed in favor of one policy instrument versus the other. ${ }^{1}$ Moreover, OECD (2014) data regarding the share of VAT tax revenues over the tax aggregate revenues unveils an increasing trend, particularly after 2008 where the financial turmoil and its side effects, e.g., higher unemployment rates, appeared.

Related to the above considerations, an extended discussion has been taking place among the EU member countries over the past two decades regarding the adoption of the appropriate principle of consumption taxation (COM 2011). Despite the fact that the origin principle is the preferred option by the EU Commission and the European Parliament, the destination principle prevails as a politically viable instrument. As described in a recent press release from the European Commission (COM 2014): “...After much political and technical consultation, it has appeared that an origin based system is not achievable and the consensus is that any definitive regime must be based on the principle of destination i.e. VAT is due at the point of destination of the goods...". Interestingly, in recent years, countries faced fiscal imbalances in their national accounts have increased their taxation, e.g., see Eurostat 2014. Switching from a destination to the origin principle may require increasing further the taxes as these countries face current account deficits. That is, taxing consumption in the source country may yield too little revenues.

The purpose of our study is to shed new light to some effects not highlighted thus far by the relevant literature and may explain the incentives of some interest groups, i.e., workers, exporters, or of the policy makers on the debate of destination versus origin based taxes. To this end, we introduce a parsimonious two country trade model where we allow for a distortive minimum wage, resulting to involuntary unemployment. This resembles the experience of numerous OECD member countries which, especially after the occurrence of the financial

\footnotetext{
${ }^{1}$ Real world evidence attests to that destination taxation in the form of a value added tax (VAT) over consumption has prevailed among OECD countries. However, the ongoing process of wider and deeper economic integration in commodity markets has raised concerns about the credibility of the destination principle, which relies on border tax adjustments. For this reason a switch to the origin principle scheme for taxing commodities in the European Union, it is considered that will prevent VAT evasion (see Nam et al. 2001).
} 
turmoil, have recorded distorted, away from the efficient, levels of production, and rising levels of unemployment.

A key result of the paper that can potentially explain the favorable bias of the EU Commission over destination-based consumption taxation is that when countries are large, i.e., accounting for terms of trade considerations in international commodity markets, and their exports are non-labor intensive then destination-based consumption taxes may have positive employment effects along with positive employment and fiscal externalities not captured by the individual national authorities. This finding perhaps contradicts a common belief that, in the presence of unemployment, higher consumption taxes exacerbate this labor market distortion. Being this true in a demand driven model, in a supply side model, when taxes are imposed on non-labor intensive commodities, then lower demand for these commodities reduces their international relative price, thus raises the relative price of labor intensive commodities and levels of employment. A similar intuition applies for the ensuing positive employment externalities in the other country. Notably, in this case, opposing effects in international product markets cancel out the emerging terms of trade effects.

When origin-based consumption taxes are implemented, an increase in their levels on non-labor intensive exporting commodities results to negative terms of trade effect, and to a positive employment effect in that country. Yet, the induced employment and the fiscal externalities are positive only when the exporting goods are substitutes in consumption. Otherwise these employment and fiscal externalities may be negative.

In our study, these and other results are unveiled in a general equilibrium model of two symmetric large open economies, with minimum wage driven unemployment, and public good provision, in the context of which we examine the fiscal, employment and welfare effects of destination and origin-based international commodity taxation. Furthermore, we compare these results to the case where international terms of trade effects are absent, i.e., small open economies in international commodity markets.

\subsection{Related Literature}

The literature on destination and origin-based principles of international commodity taxation is quite extensive and diverse in regards to the issues it raises. A voluminous strand of this literature examines the implications of the two taxation principles in the context of general 
equilibrium models with perfectly competitive product and factor, e.g., labor and capital, markets.

In this context, among others, Mintz and Tulkens (1986), characterize a non-cooperative equilibrium between two regions choosing an origin-based tax levied on the same commodity. Kanbur and Keen (1993) provide a comparison between tax competition, when taxes are set according to the destination principle, and tax cooperation in a model of two countries differing by size. Lockwood (1993) examines the effect of switching from the destination to the origin principle of taxation on non-cooperative commodity tax equilibrium. Haufler (1994) examines the effects of a general commodity taxation under the restricted origin principle, ${ }^{2}$ when countries of an economic union are small vis-à-vis the rest of the world in international product markets. Lockwood (2001) analyzes commodity tax competition under destination and origin principles, accounting for international factor mobility vs. immobility and three types of potential spillovers, (i) consumer price spillover, (ii) producer price/terms of trade spillover, and (iii) rent spillovers. Keen and Wildasin (2004) conclude that Pareto efficient international taxation may require production inefficiencies in the allocation of world resources, and thus the desirability of the destination basis for commodity taxation ${ }^{3}$ and of the residence principle for capital income taxation does not hold. A second strand of this literature, not relevant to our study, examines the implications of international commodity taxation in the context of full employment and imperfectly competitive product markets, e.g., Keen and Lahiri (1998), Lockwood (2001), Haufler and Pflüger (2004, 2007), Haufler, et al. (2005), Behrens, et al. (2007, 2009).

The aforementioned extensive literature has not considered explicitly the effects of the alternative regimes of international commodity taxation in the presence of factor markets distortions, e.g., unemployment in labor markets. To the best of our knowledge, the notable exception is the study by Moriconi and Sato (2009), who in a general equilibrium model of two symmetric small open economies with public good provision and unemployment, due to a minimum wage, examine the impact of international tax competition on welfare and unemployment. Some of their main findings are: (i) under the destination principle, commodity

\footnotetext{
${ }^{2}$ Intra-union trade is taxed in the country of origin, while trade between the union and the rest of the world is taxed in the destination country.

${ }^{3}$ Any Pareto-efficient tax structure is characterized by production efficiency as long as pure profits are taxed at 100 percent rate, and there are no restrictions on the distorting instruments that can be applied (Diamond and Mirrlees 1971). On the basis of this principle, destination-based consumption taxes are superior to origin-based taxes.
} 
taxation has a negative employment externality. Non-cooperative equilibrium tax rates are higher than the optimal level, (ii) under the origin principle, commodity taxation has a positive employment externality if and only if the two goods are substitutes in consumption. Noncooperative equilibrium tax rates are higher than the optimal level if the two goods are complements in consumption. If the goods are substitutes, tax rates in a non-cooperative equilibrium are higher (lower) than the optimal level if the marginal utility of the public good is sufficiently small (large), and (iii) when revenues from consumption taxes are lump-sum distributed to households, the unemployment rate is higher and welfare is lower under the destination rather than under the origin principle if and only if the wage premium is high.

In closing this section, we highlight the crucial differences between the Moriconi and Sato (2009) and present models. Their framework is a demand driven one with constant world commodity prices, where one unit of consumption generates one unit of production and one unit of employment. Instead, our model is a more general supply side framework with variable world commodity prices and many factors of production, where minimum wage induced unemployment is also related to the factor intensity of commodities in production. Our analysis reproduces the Moriconi and Sato (2009) results, rendering them as a special case of the present model.

\section{The Model}

Consider two symmetric large open economies, Home and Foreign, with unemployment and public good provision. The variables of the latter country are denoted throughout by an asterisk $(*)$. A representative household resides in each country, consuming three traded goods: $x, y$ and $z$. Good $z$ is the numeraire good, produced in both countries, is untaxed and its price equals to one. ${ }^{4}$ Good $x$ is produced only by the Home, and good $y$ is produced only by the Foreign. In each country there are at least as many fully flex-price, fully-employed factors as there are fully flex-price traded goods. An additional factor, labor, called fixed-price factor, is paid a binding, above the market clearing level, minimum wage $\bar{w}\left(\bar{w}^{*}\right)$, in terms of the

\footnotetext{
${ }^{4}$ In the literature of commodity tax competition, the assumption of untaxed numeraire commodity is a common one, since all tax systems exempt from taxation a share of national product. Theoretically, if all commodities, including the numeraire are taxed, then under general conditions the destination and origin-based systems of commodity taxation are equivalent, e.g., see Lockwood (2001), Haufler and Pflüger (2007) and Moriconi and Sato (2009).
} 
numeraire. Labor supply in each economy is infinitely elastic, and all workers inelastically supply one unit of labor at this minimum wage $\bar{w}\left(\bar{w}^{*}\right) .{ }^{5}$ Employment $L\left(L^{*}\right)$ is smaller than each economy's labor endowment $\bar{L}\left(\bar{L}^{*}\right)$. As a result, there is involuntary unemployment in the two economies. Let $p_{x}$ and $p_{y}^{*}$ respectively denote the producers price of $x$ in Home and of $y$ in Foreign.

Using duality, we define the production side of each economy with the binding minimum wage and involuntary unemployment. Following, among others, Kreickemeier (2005), Falvey and Kreickemeier (2009), we define, for Home, $\pi(1, P, k)=\max _{z, v}\{z+P v:(z, v, k)\}$ to be the socalled restricted revenue function which maximizes the income of the fully employed factors, $v \equiv(x,-L)$ is the vector of output $x$ and employment (negative output), $P \equiv\left(p_{x}, \bar{w}\right)$ is the vector of corresponding prices and $k$ is the vector of fully employed factors of production. To ensure differentiability of the $\pi($.) function, we assume the existence of at least as many flex-price factors as flex-price goods. Then, from Hotteling's Lemma:

$\left(\partial \pi / \partial p_{x}\right)=\pi_{p_{x}}=x(1, P, k)$ is the supply function of $x$ $-(\partial \pi / \partial \bar{w})=-\pi_{\bar{w}}=L(1, P, k)$ is the employment level, and $\left(\partial L / \partial p_{x}\right)=L_{p_{x}}=-\left(\partial^{2} \pi / \partial \bar{w} \partial p_{x}\right)=-\pi_{\bar{w} p_{x}}$.

Similarly for Foreign we define $y^{*}=\pi_{p_{y}^{*}}^{*}\left(1, P^{*}, k^{*}\right), L^{*}\left(1, P^{*}, k^{*}\right)=\pi_{\vec{w}^{*}}^{*}\left(1, P^{*}, k^{*}\right)$ and $L_{p_{y}^{*}}^{*}=-\pi_{\vec{w}^{*} p_{y}^{*}}^{*}$ where $P^{*} \equiv\left(p_{y}^{*}, \bar{w}^{*}\right)$. Then, each country's economy-wide value of production with minimum wage and involuntary unemployment is defined by the gross-domestic-product function (GDP) as $\quad G D P=\pi(1, P, k)+\bar{w} L(1, P, k)=R\left(1, p_{x}, \bar{w}, L\left(1, p_{x}, \bar{w}\right)\right) \quad$ for $\quad$ Home, and $R^{*}=\left(1, p_{y}^{*}, \bar{w}^{*}, L^{*}\left(1, p_{y}^{*}, \bar{w}^{*}\right)\right)$, for Foreign, e.g., see Neary (1985). That is, in a minimum wage economy with involuntary unemployment, the $G D P$ equals the $G D P$ of the economy at

\footnotetext{
${ }^{5}$ Moriconi and Sato (2009) consider a group of employed workers receiving the minimum wage $\bar{w}\left(\bar{w}^{*}\right)$ and another group of workers totally unemployed, living on an exogenous subsistence wage (reservation income) earned from non-firm activities. Without loss of generality for our results, we depart from this formulation, although it is easily modeled in our framework. Thus, purely for analytical convenience, we consider all unemployed in the economy receiving no income from any source.
} 
full employment when labor endowment equals the equilibrium demand for labor under the binding minimum wage. By the properties of the GDP function, $\left(\partial R / \partial p_{x}\right)=R_{p_{x}}=x,-(\partial R / \partial \bar{w})=-R_{\bar{w}}=L, \quad$ and $\quad L_{p_{x}}=-R_{\bar{w} p_{x}}=-\left(\partial^{2} R / \partial \bar{w} \partial p_{x}\right) \quad$ is interpreted as a general equilibrium measure of factor intensity, see Dixit and Norman (1980). If $L_{p_{x}}>0$, that is, if a higher $p_{x}$ raises employment, we call good $x$ labor intensive, while in the opposite case we call it non-labor intensive. Similarly for the Foreign $y=R_{p_{y}^{*}}^{*}, L^{*}=-R_{\bar{w}^{*}}^{*}$ and $L_{p_{y}^{*}}^{*}>(<) 0$.

A representative household in each country derives utility from consumption of the traded goods $(x, y, z)$, and of the public consumption $\operatorname{good}(g)$. The demand side is described by the minimum expenditure function $E\left(1, q_{x}, q_{y}, g, u\right)$ capturing the minimum expenditure required to achieve a given level of utility $u$ at consumer prices $q_{x}$ and $q_{y}$ and level of the public good $g$. Regarding consumer prices, the government levies a specific consumption tax $t_{i}$ according to the destination $(i=d)$ or origin $(i=o)$ principle. When consumption is taxed according to the destination principle, then $q_{x}=p_{x}+t_{d}$ and $q_{y}=p_{y}^{*}+t_{d}$. When it is taxed according to the origin principle, $q_{x}=p_{x}+t_{o}$ and $q_{y}=p_{y}^{*}+t_{o}^{*}$. By Shepard's Lemma, $E_{q_{j}}=\left(\partial E / \partial q_{j}\right), j=x, y$ denotes the compensated demand for the $j^{\text {th }}$ commodity, $E_{g}$ is the so-called marginal willingness to pay for the public good, and $E_{u}$ is the reciprocal of the marginal utility of income. The expenditure function is strictly concave in consumer prices i.e., $E_{q_{x} q_{x}}<0$, and $E_{q_{y} q_{y}}<0$, and the two commodities can be either substitutes i.e., $E_{q_{x} q_{y}}>0$ or complements $E_{q_{x} q_{y}}<0$, in consumption. It is assumed that the traded goods and public good are separable in consumption, i.e., $E_{q_{x} g}=E_{q_{y} g}=0$, and that all income effects fall on the numeraire commodity, i.e., $E_{q_{x} u}=E_{q_{y} u}=0 .{ }^{6}$ Similarly, Foreign's demand side is summarized by the minimum expenditure function $E^{*}\left(1, q_{x}^{*}, q_{y}^{*}, g^{*}, u^{*}\right)$, where when consumption is taxed according to the destination

\footnotetext{
${ }^{6}$ These assumptions are supported by a quasi-linear utility function, e.g., $V(x, y, z, g)=v(x, y)+z+f(g)$. Such is the utility function used, by and large, in the relevant literature, e.g., see Lockwood (2001), Haufler and Pflüger (2007) and Moriconi and Sato (2009).
} 
principle, then $q_{x}^{*}=p_{x}+t_{d}^{*}$ and $q_{y}^{*}=p_{y}^{*}+t_{d}^{*}$, and when it is taxed according to the origin principle, then $q_{x}^{*}=p_{x}+t_{o}$ and $q_{y}^{*}=p_{y}^{*}+t_{o}^{*}$. The partial derivatives of the $E^{*}($.$) function with$ respect to its arguments result to the same variables as those of when differentiating $E(.){ }^{7}$

Each country's government finances the provision of the public consumption good, $g\left(g^{*}\right)$, through consumption tax revenues. Assuming both governments maintain balanced budgets, under the destination principle we have: ${ }^{8}$

$$
g_{d}=t_{d}\left(E_{q_{x}}+E_{q_{y}}\right) \text { and } g_{d}^{*}=t_{d}^{*}\left(E_{q_{x}^{*}}^{*}+E_{q_{y}^{*}}^{*}\right)
$$

and under the origin principle we have:

$$
g_{o}=t_{o}\left(E_{q_{x}}+E_{q_{x}^{*}}^{*}\right) \text { and } g_{o}^{*}=t_{o}^{*}\left(E_{q_{y}}+E_{q_{y}^{*}}^{*}\right) .
$$

A country's income expenditure identity requires that the representative household's spending on privately produced goods is equal to the country's GDP. Thus, under the two tax principles $(i=d, o)$, for Home and Foreign respectively we have:

$$
\begin{aligned}
& E\left(1, q_{x}, q_{y}, g, u\right)=R\left(1, p_{x}, \bar{w}, L\left(1, p_{x}, \bar{w}\right)\right), \text { and } \\
& E^{*}\left(1, q_{x}^{*}, q_{y}^{*}, g^{*}, u^{*}\right)=R^{*}\left(1, p_{y}^{*}, \bar{w}^{*}, L^{*}\left(1, p_{y}^{*}, \bar{w}^{*}\right)\right) .
\end{aligned}
$$

Equilibrium in the world commodity markets for the two goods is given by:

$$
\begin{aligned}
& E_{q_{x}}\left(1, q_{x}, q_{y}, g, u\right)+E_{q_{x}^{*}}^{*}\left(1, q_{x}^{*}, q_{y}^{*}, g^{*}, u^{*}\right)=R_{p_{x}}\left(1, p_{x}, \bar{w}, L\left(1, p_{x}, \bar{w}\right)\right), \text { and } \\
& E_{q_{y}}\left(1, q_{x}, q_{y}, g, u\right)+E_{q_{y}^{*}}^{*}\left(1, q_{x}^{*}, q_{y}^{*}, g^{*}, u^{*}\right)=R_{p_{y}^{*}}^{*}\left(1, p_{y}^{*}, \bar{w}^{*}, L^{*}\left(1, p_{y}^{*}, \bar{w}^{*}\right)\right) .
\end{aligned}
$$

Equilibrium in the two-country model under the destination principle is described by conditions (1), and (3)-(6), while under the origin principle by conditions (2)-(6). In both cases we have a system of six equations in $p_{x}, p_{y}^{*}, g, g^{*}, u$ and $u^{*}$.

\footnotetext{
${ }^{7}$ Countries are assumed symmetric in the sense of having identical preferences and production technologies. However, despite of being symmetric each produces, with identical production technology, a different good along with the homogeneous numeraire. See Moriconi and Sato (2006) p.8, where $x=K^{\alpha} L^{1-\alpha}$ and $y^{*}=K^{* \alpha} L^{* 1-\alpha}$.

${ }^{8}$ For analytical simplicity we assume that the unit cost of public good provision is constant and equal to one in both countries, e.g., see Moriconi and Sato (2009).
} 


\section{Commodity tax competition and producer prices}

Differentiating equations (5) and (6), changes in producer prices due to changes in consumption taxes are given as follows. Under the destination principle we obtain:

$$
\begin{gathered}
\Delta d p_{x}=\left\{\begin{array}{l}
{\left[-Z_{y}\left(E_{q_{x} q_{x}}+E_{q_{x} q_{y}}\right)+\left(E_{q_{y} q_{x}}+E_{q_{y} q_{y}}\right)\left(E_{q_{x} q_{y}}+E_{q_{x}^{*} q_{y}^{*}}^{*}\right)\right] d t_{d}+} \\
{\left[-Z_{y}\left(E_{q_{x}^{*} q_{x}^{*}}^{*}+E_{q_{x}^{*} q_{y}^{*}}^{*}\right)+\left(E_{q_{y}^{*} q_{x}^{*}}^{*}+E_{q_{y}^{*} q_{y}^{*}}^{*}\right)\left(E_{q_{x} q_{y}}+E_{q_{x}^{*} q_{y}^{*}}^{*}\right)\right] d t_{d}^{*}}
\end{array}\right\} \\
\Delta d p_{y}^{*}=\left\{\begin{array}{l}
{\left[-Z_{x}\left(E_{q_{y} q_{y}}+E_{q_{y} q_{x}}\right)+\left(E_{q_{x} q_{x}}+E_{q_{x} q_{y}}\right)\left(E_{q_{y} q_{x}}+E_{q_{y}^{*} q_{x}^{*}}^{*}\right)\right] d t_{d}^{*}+} \\
{\left[-Z_{x}\left(E_{q_{y}^{*} q_{x}^{*}}^{*}+E_{q_{y}^{*} q_{y}^{*}}^{*}\right)+\left(E_{q_{x}^{*} q_{x}^{*}}^{*}+E_{q_{x}^{*} q_{y}^{*}}^{*}\right)\left(E_{q_{y} q_{x}}+E_{q_{y}^{*} q_{x}^{*}}^{*}\right)\right] d t_{d}^{*}}
\end{array}\right\},
\end{gathered}
$$

Where $\quad \Delta=Z_{x} Z_{y}-\left(E_{q_{x} q_{y}}+E_{q_{x}^{*} q_{y}^{*}}^{*}\right)\left(E_{q_{y} q_{x}}+E_{q_{y}^{*} q_{x}^{*}}^{*}\right)>0, \quad$ see the Appendix, and $Z_{y}=\left(E_{q_{y} q_{y}}+E_{q_{y}^{*} q_{y}^{*}}^{*}-R_{p_{y}^{*} p_{y}^{*}}^{*}\right)<0$ and $Z_{x}=\left(E_{q_{x} q_{x}}+E_{q_{x}^{*} q_{x}^{*}}^{*}-R_{p_{x} p_{x}}\right)<0$ respectively denote changes in the world excess demands for commodities $x$ and $y$ due to changes in the tax rates $t_{d}$ and $t_{d}^{*}$. Details for the derivations of equations (7) and (8) are given by equations (A.1)-(A.2) in the Appendix. These equations indicate that under the destination principle, when countries are symmetric, an increase in the consumption tax by either country lowers producer prices for both commodities $x$ and $y$, i.e., $\left(d p_{x} / d t_{d}\right)<0,\left(d p_{x} / d t_{d}^{*}\right)<0,\left(d p_{y}^{*} / d t_{d}^{*}\right)<0,\left(d p_{y}^{*} / d t_{d}\right)<0$, if the direct substitution effect of the tax increase dominates its cross-substitution effect (see equation A. 2 in the Appendix). ${ }^{9}$ The result holds independently of the relationship, i.e., substitutability or complementarity, of the two goods in consumption.

Under the origin principle of commodity taxation, the differentiation of equations (5)-(6) yields:

$$
\begin{aligned}
& \Delta d p_{x}=\left[-Z_{y}\left(E_{q_{x} q_{x}}+E_{q_{x}^{*} q_{x}^{*}}^{*}\right)+\left(E_{q_{x} q_{y}}+E_{q_{x}^{*} q_{y}^{*}}^{*}\right)^{2}\right] d t_{o}+\left(E_{q_{x} q_{y}}+E_{q_{x}^{*} q_{y}^{*}}^{*}\right) R_{p_{y}^{*} p_{y}^{*}}^{*} d t_{o}^{*} \\
& \Delta d p_{y}^{*}=\left(E_{q_{y} q_{x}}+E_{q_{y}^{*} q_{x}^{*}}^{*}\right) R_{p_{x} p_{x}} d t_{o}+\left[-Z_{x}\left(E_{q_{y} q_{y}}+E_{q_{y}^{*} q_{y}^{*}}^{*}\right)+\left(E_{q_{x} q_{y}}+E_{q_{x}^{*} q_{y}^{*}}^{*}\right)^{2}\right] d t_{o}^{*}
\end{aligned}
$$

\footnotetext{
${ }^{9}$ This is a widely used assumption in the international trade-public finance nexus, e.g., see Emran (2005) and Emran and Stiglitz (2005). We also maintain this assumption throughout the analysis.
} 
Details for these derivations are given by equations (A.3)-(A.4) in the Appendix. Under originbased consumption taxes, equations (9) and (10), on the one hand, indicate that independently of the relationship between the two goods in consumption, an increase in a country's own consumption tax rate lower's the local producers' price, i.e., $d p_{x} / d t_{o}<0$ and $d p_{y}^{*} / d t_{o}^{*}<0$. On the other hand, a higher consumption tax by one country reduces (increases) the other country's producers price, i.e., $d p_{x} / d t_{o}^{*}<(>) 0$ and $d p_{y}^{*} / d t_{o}<(>) 0$, if commodities are complements (substitutes) in consumption. The following Lemma summarizes these results.

Lemma 1: Consider two symmetric large open economies with unemployment. Destination or origin-based taxes are levied on the consumption of traded commodities. Then:

- Under the destination principle, a higher consumption tax by either country reduces producers' prices in both countries.

- Under the origin principle, a higher consumption tax by either country lowers the local producers' price and it lowers (raises) the producers' price in the other country if the two commodities are complements (substitutes) in consumption.

\section{Commodity tax competition, unemployment and welfare}

We examine the welfare effects of the two principles of commodity taxation with endogenous terms of trade, unemployment, and provision of a local public good. Due to the assumed symmetry of the two countries, it suffices to examine the effects of commodity taxation on one country's, e.g., Home, welfare, and equivalently are derived the effects of commodity tax competition on Foreign's welfare.

\subsection{Destination-based consumption taxes, unemployment and welfare}

Differentiating equations (1), (3) and (4) with respect to consumption taxes $t_{d}$ and $t_{d}^{*}$, the effects on the two countries welfare levels are as follows:

$$
E_{u} d u=A_{t_{d}} d t_{d}+A_{t_{d}^{*}} d t_{d}^{*}, \quad E_{u^{*}}^{*} d u^{*}=B_{t_{d}} d t_{d}+B_{t_{d}^{*}} d t_{d}^{*}
$$

where, 


$$
\begin{aligned}
& A_{t_{d}}=\left\{\begin{array}{l}
\underbrace{-\left[\left(E_{q_{x}}-R_{p_{x}}\right) \frac{d p_{x}}{d t_{d}}+E_{q_{y}} \frac{d p_{y}^{*}}{d t_{d}}\right]}_{\text {terms-of-trade effect }}+\underbrace{\bar{w} L_{p_{x}} \frac{d p_{x}}{d t_{d}}}_{\text {employment effect }} \\
-\underbrace{\left(1+E_{g}\right)\left(E_{q_{x}}+E_{q_{y}}\right)-E_{g} t_{d}\left[\left(E_{q_{x} q_{x}}+E_{q_{y} q_{x}}\right)\left(1+\frac{d p_{x}}{d t_{d}}\right)+\left(E_{q_{x} q_{y}}+E_{q_{y} q_{y}}\right)\left(1+\frac{d p_{y}^{*}}{d t_{d}}\right)\right]}_{\text {fiscal effect }}
\end{array}\right\} \\
& A_{t_{d}^{*}}=\underbrace{-\left[\left(E_{q_{x}}-R_{p_{x}}\right) \frac{d p_{x}}{d t_{d}^{*}}+E_{q_{y}} \frac{d p_{y}^{*}}{d t_{d}^{*}}\right]}_{\text {terms-of-trade externality }}+\underbrace{\bar{w} L_{p_{x}} \frac{d p_{x}}{d t_{d}^{*}}}_{\text {employment externality }}-\underbrace{E_{g} t_{d}\left[\left(E_{q_{x} q_{x}}+E_{q_{y} q_{x}}\right) \frac{d p_{x}}{d t_{d}^{*}}+\left(E_{q_{x} q_{y}}+E_{q_{y} q_{y}}\right) \frac{d p_{y}^{*}}{d t_{d}^{*}}\right]}_{\text {fiscal externality }},
\end{aligned}
$$

$B_{t_{d}}$ and $B_{t_{d}^{*}}$ for Foreign are equivalently defined to $A_{t_{d}^{*}}$ and $A_{t_{d}}$. Under the invoked symmetry, $\left(1+\frac{d p_{x}}{d t_{d}}\right)$ and $\left(1+\frac{d p_{y}^{*}}{d t_{d}}\right)$ are positive. ${ }^{10}$ The expressions $A_{t_{d}}$ and $A_{t_{d}^{*}}$, respectively, decompose the impact of $t_{d}$ and $t_{d}^{*}$ (externalities) on Home's welfare. In regards to $A_{t_{d}}$, the first right-handside term we call the terms-of-trade effect of the higher $t_{d}$ on the country's welfare. Since, both $\left(d p_{x} / d t_{d}\right)$ and $\left(d p_{y}^{*} / d t_{d}\right)$ are negative, then, on the one hand, Home's trade balance worsens due to lower value of exports, i.e., $-\left(E_{q_{x}}-R_{p_{x}}\right)\left(d p_{x} / d t_{d}\right)<0$, and, on the other, it improves due to lower value of imports or consumption of $y$, i.e., $-E_{q_{y}}\left(d p_{y}^{*} / d t_{d}\right)>0$. Given that each country produces a single commodity which it exports, then, by equilibrium conditions (5) and (6), it is that one country's exports equal the other country's consumption (imports) of this commodity, i.e., $-\left(E_{q_{x}}-R_{p_{x}}\right)=E_{q_{x}^{*}}^{*}$ and $-\left(E_{q_{y}^{*}}^{*}-R_{p_{y}^{*}}^{*}\right)=E_{q_{y}}$. Furthermore, because of the assumed

10 From equations (7) and (8), $\quad-1<\left(d p_{x} / d t_{d}\right)<0$ and $-1<\left(d p_{y}^{*} / d t_{d}\right)<0$. Then, $\quad\left(1+\frac{d p_{x}}{d t_{d}}\right)=\frac{d q_{x}}{d t_{d}} \quad$ and $\left(1+\frac{d p_{y}^{*}}{d t_{d}}\right)=\frac{d q_{y}}{d t_{d}}$ are positive. 
symmetry, it also holds that $E_{q_{x}^{*}}^{*}=E_{q_{y}}$. As a result, these two effects cancel each other out, thus neutralizing the terms-of-trade effect of the higher $t_{d}$ on the country's welfare. ${ }^{11}$

The employment effect of the higher $t_{d}$ on Home's welfare is positive (negative), i.e., $\bar{w} L_{p_{x}}\left(d p_{x} / d t_{d}\right)>(<) 0$, depending on whether the non-numeraire commodity $x$ is non-labor (labor)-intensive in production, i.e., $L_{p_{x}}<(>) 0 .^{12}$

The third term in the expression $A_{t_{d}}$ is the fiscal effect of the higher $t_{d}$ on the country's welfare, capturing the welfare impact of changes in the country's tax base and thus its ability to provide the public good. The term $\left(E_{g}+1\right)\left(E_{q_{x}}+E_{q_{y}}\right)$ shows the level of tax revenue at a given rate $t_{d}$. If $\left(E_{g}+1\right)<(>) 0$ we say that the public good is socially under (over-) provided. Optimal provision of $g$ dictates that $\left(E_{g}+1\right)=0$, i.e., the Samuelson rule for optimal public good provision whereby the household's marginal willingness to pay for a unit of $g$ equals to its marginal cost. ${ }^{13}$ The second component of the fiscal effect indicates that since $\left(1+\frac{d p_{x}}{d t_{d}}\right)>0$ and $\left(1+\frac{d p_{y}^{*}}{d t_{d}}\right)>0$, then, a higher consumption tax reduces public sector revenues, due to lower consumptions of $x$ and $y$, thus leading to lower levels of public good provision and welfare.

Similar arguments to those above hold for the impact of a higher $t_{d}^{*}$ on Home's welfare, through induced terms-of-trade effect, and the employment and fiscal externalities. Thus, considering symmetric countries, and assuming that exported goods are non-labor intensive, then

\footnotetext{
${ }^{11}$ The first bracketed term in $A_{t_{d}}$ becomes $E_{q_{y}}\left(\frac{d p_{y}^{*}}{d t_{d}}-\frac{d p_{x}}{d t_{d}}\right)$, which by equations (7)-(8) equals to zero.

${ }^{12}$ For example, when the price of the exported good falls due to a higher $t_{d}$, and the commodity is non-labor intensive, employment in the production of the numeraire commodity rises by more than it falls in the exported good sector, thus inducing a positive employment effect.

${ }^{13}$ The assumption of optimal provision of the public good can be easily supported by introducing lump-sum taxes in equations (1), (3) and (4) and assuming that their levels are set by each government non-cooperatively (Nash) in order to ensure the optimal provision of $g$ and $g^{*}$. Since in our analysis the addition of lump-sum taxes makes no difference whatsoever for the results, wherever required, we simply assume that $g$ and $g^{*}$ are locally optimally provided.
} 
a higher consumption tax $t_{d}^{*}$ by Foreign exerts no terms-of-trade effect on Home's welfare, and it entails positive employment and fiscal externalities. The following Proposition highlights some of these results:

Proposition 1: Consider two symmetric large open economies with unemployment. Destinationbased taxes are levied on consumptions of traded commodities. Then, a higher destination-based consumption tax by either country:

(i) exerts no terms-of-trade externality,

(ii) entails a positive (negative) employment effect, and a positive (negative) employment externality abroad, if the exported goods are non-labor (labor) intensive,

(iii) entails a negative fiscal effect if the public good is optimally or over-provided, and entails a positive fiscal externality.

Setting $E_{u}\left(d u / d t_{d}\right)=A_{t_{d}}=0$ and $E_{u^{*}}^{*}\left(d u^{*} / d t_{d}^{*}\right)=B_{t_{d}^{*}}=0$ in equations (11), we obtain the two countries' best-response functions which yield the Nash (non-cooperative) consumption tax rates $\left(t_{d}^{N}, t_{d}^{*^{N}}\right)$ under the destination-based commodity taxation:

$$
\begin{aligned}
& t_{d}^{N}=\Omega_{d}^{-1}\left[\bar{w} L_{p_{x}} \frac{d p_{x}}{d t_{d}}-\left(1+E_{g}\right)\left(E_{q_{x}}+E_{q_{y}}\right)\right] \\
& t_{d}^{* N}=\Omega_{d}^{*-1}\left[\bar{w}^{*} L_{p_{y}^{*}}^{*} \frac{d p_{y}^{*}}{d t_{d}^{*}}-\left(1+E_{g^{*}}^{*}\right)\left(E_{q_{x}^{*}}^{*}+E_{q_{y}^{*}}^{*}\right)\right],
\end{aligned}
$$

where $\Omega_{d}=E_{g}\left[\left(E_{q_{x} q_{x}}+E_{q_{y} q_{x}}\right)\left(1+\frac{d p_{x}}{d t_{d}}\right)+\left(E_{q_{x} q_{y}}+E_{q_{y} q_{y}}\right)\left(1+\frac{d p_{y}^{*}}{d t_{d}}\right)\right]$, and $\Omega_{d}^{*} \quad$ is equivalently defined, and both are positive. Equations (12) indicate that the Nash equilibrium destinationbased consumption taxes are positive if (i) a higher destination-based consumption tax entails a positive employment effect, and (ii) there is no over-provision of the public good.

To ascertain whether a country's Nash tax rate $\left(t_{d}^{N}, t_{d}^{*_{N}}\right)$ is equally efficient to the cooperative one $\left(t_{d}^{c}, t_{d}^{* c}\right)$, we evaluate at Nash equilibrium the impact of the higher $\operatorname{tax}\left(t_{d}, t_{d}^{*}\right)$ on the countries joint welfare. When countries choose consumption taxes so as to maximize joint welfare, the cooperative equilibrium destination-based consumption taxes $\left(t_{d}^{c}, t_{d}^{*_{c}}\right)$ are 
determined by setting $\quad E_{u}\left(d u / d t_{d}\right)+E_{u^{*}}^{*}\left(d u^{*} / d t_{d}\right)=0 \quad$ for $\quad$ Home, and $E_{u}\left(d u / d t_{d}^{*}\right)+E_{u^{*}}^{*}\left(d u^{*} / d t_{d}^{*}\right)=0$ for Foreign. Evaluating these joint welfare functions at Nash equilibrium, it suffices to sign the $E_{u^{*}}^{*}\left(d u^{*} / d t_{d}\right)$ and $E_{u}\left(d u / d t_{d}^{*}\right)$ terms, respectively, since at Nash equilibrium $E_{u}\left(d u / d t_{d}\right)=E_{u^{*}}^{*}\left(d u^{*} / d t_{d}^{*}\right)=0$. Doing so, the effect of a higher destinationbased consumption tax by Home on Foreign's welfare, evaluated at Nash equilibrium values, is:

$$
\left.E_{u^{*}}^{*} \frac{d u^{*}}{d t_{d}}\right|_{t_{d}^{* N}}=\left.B_{t_{d}}\right|_{t_{d}^{* N}}=\underbrace{\bar{w}^{*} L_{p_{y}^{*}}^{*} \frac{d p_{y}^{*}}{d t_{d}}}_{\text {employment externality }}-\underbrace{E_{g^{*}}^{*} t_{d}^{* N}\left[\left(E_{q_{x}^{*} q_{x}^{*}}^{*}+E_{q_{y}^{*} q_{x}^{*}}^{*}\right) \frac{d p_{x}}{d t_{d}}+\left(E_{q_{x}^{*} q_{y}^{*}}^{*}+E_{q_{y}^{*} q_{y}^{*}}^{*}\right) \frac{d p_{y}^{*}}{d t_{d}}\right]}_{\text {fiscal externality }} .
$$

The sign of the expression in equation (13) is positive, provided that there is no over-provision of the public good, and that exported goods are non-labor intensive. ${ }^{14}$ Thus, since $\left.E_{u^{*}}^{*}\left(d u^{*} / d t_{d}\right)\right|_{t_{d}^{* N}}>0$, it is to say that Home's Nash equilibrium destination-based consumption tax is inefficiently lower compared to the country's cooperative tax rate, i.e., $t_{d}^{N}<t_{d}^{c}$. If any of the above assumptions does not hold, then it is possible that $\left.E_{u^{*}}^{*}\left(d u^{*} / d t_{d}\right)\right|_{t_{d}^{* N}}<0$, implying that $t_{d}^{N}>t_{d}^{c}$. The following Proposition summarizes this discussion.

Proposition 2: Consider two symmetric large open economies with unemployment. Destinationbased taxes are levied on the consumption of traded goods. If (i) the exported goods are nonlabor intensive, and (ii) there is no over-provision of the public good, then, the Nash equilibrium destination-based consumption tax is positive and lower than its corresponding cooperative rate.

Within the present context the case of small open economies, i.e., fixed producers' prices, can be reproduced by setting $d p_{x}=d p_{y}^{*}=0$ in equations (11). Because producers' prices are constant, the modified equations (11) indicate that there is neither an employment effect locally, nor an induced employment and fiscal externality. The following Corollary states these results.

Corollary 1: Consider two symmetric small open economies with unemployment. The Nash equilibrium destination-based consumption tax $(i)$ is positive if there is no over-provision of the public good, and (ii) is equally efficient to its cooperative rate.

\footnotetext{
${ }^{14}$ Recall from equations (12) that under these assumptions, $t_{d}^{* N}$ is positive.
} 


\subsection{Origin-based consumption taxes, unemployment and welfare}

Now consider the case where origin-based consumption taxes are levied on the traded commodities $x$ and $y$. Differentiating equations (2)-(4) with respect to the origin-based consumption taxes $t_{o}$ and $t_{o}^{*}$ the effects on the two countries welfare levels are as follows:

$$
E_{u} d u=A_{t_{o}} d t_{o}+A_{t_{o}} d t_{o}^{*}, \quad E_{u^{*}}^{*} d u^{*}=B_{t_{o}} d t_{o}+B_{t_{o}} d t_{o}^{*},
$$

where,

$$
\begin{aligned}
& A_{t_{o}}=\left\{\begin{array}{l}
\underbrace{E_{q_{y}}\left(\frac{d p_{x}}{d t_{o}}-\frac{d p_{y}^{*}}{d t_{o}}\right)}_{\text {terms-of-trade effect }}+\underbrace{\bar{w} L_{p_{x}} \frac{d p_{x}}{d t_{0}}-E_{\text {private consumption effect }}^{E_{q_{x}}}}_{\text {employment effect }} \\
-\underbrace{-E_{g}\left\{\left(E_{q_{x}}+E_{q_{x}^{*}}^{*}\right)+t_{o}\left[\left(E_{q_{x} q_{x}}+E_{q_{x}^{*} q_{x}^{*}}^{*}\right)\left(1+\frac{d p_{x}}{d t_{o}}\right)+\left(E_{q_{x} q_{y}}+E_{q_{x}^{*} q_{y}^{*}}^{*}\right) \frac{d p_{y}^{*}}{d t_{o}}\right]\right\}}_{\text {fiscal effect }}\},
\end{array}\right\} \\
& A_{t_{o}^{*}}=\left\{\begin{array}{l}
\underbrace{E_{q_{y}}\left(\frac{d p_{x}}{d t_{o}^{*}}-\frac{d p_{y}^{*}}{d t_{o}^{*}}\right)}_{\text {terms-of-trade externality }}+\underbrace{\bar{w} L_{p_{x}} \frac{d p_{x}}{d t_{0}^{*}}}_{\text {employment externality }}-\underbrace{E_{q_{y}}}_{\text {fiscal externality }} \\
-\underbrace{E_{0}^{*} \text { consumption externality }}_{p_{g} t_{o} \Delta^{-1}\left(E_{q_{x} q_{y}}+E_{q_{x}^{*} q_{y}^{*}}^{*}\right) R_{p_{x} p_{x}} R_{p_{y}^{*} p_{y}^{*}}^{*}}
\end{array}\right\}
\end{aligned}
$$

$B_{t_{o}}$ and $B_{t_{*}^{*}}$ for Foreign are equivalently defined to $A_{t_{*}^{*}}$ and $A_{t_{o}} \cdot{ }^{15}$ Recall from equations (9) and (10) that $\left(d p_{x} / d t_{o}\right)$ and $\left(d p_{y}^{*} / d t_{o}^{*}\right)$ are both negative, and that $d p_{x} / d t_{o}^{*}<(>) 0$ and $d p_{y}^{*} / d t_{o}<(>) 0$, depending on whether commodities are complements

15 The complete expression for the fiscal externality of a higher $t_{o}^{*}$ on Home's welfare is $-E_{g} t_{o}\left[\left(E_{q_{x} q_{y}}+E_{q_{x}^{*} q_{y}^{*}}^{*}\right)\left(1+\frac{d p_{y}^{*}}{d t_{o}^{*}}\right)+\left(E_{q_{x} q_{x}}+E_{q_{x}^{*} q_{x}^{*}}^{*}\right) \frac{d p_{x}}{d t_{o}^{*}}\right]$. Using equations (9) and (10), after some algebra, we obtain the fiscal externality of $t_{o}^{*}$ in the expression $\mathrm{A}_{t^{*}}$. 
(substitutes) in consumption. Then, it can be shown that $\left(1+\frac{d p_{x}}{d t_{o}}\right)$ and $\left(1+\frac{d p_{y}^{*}}{d t_{o}^{*}}\right)$ are positive. $^{16}$ Equation (A.5) shows that under the symmetry assumption the term $\left(\frac{d p_{x}}{d t_{o}}-\frac{d p_{y}^{*}}{d t_{o}}\right)$ is negative regardless of whether commodities are substitutes or complements in consumption. The expressions $A_{t_{o}}$ and $A_{t_{o}^{*}}$, respectively, decompose the effects of $t_{o}$ and $t_{o}^{*}$ (externalities) on Home's welfare, and similarly, $B_{t_{o}}$ and $B_{t_{o}^{*}}$ capture the effect of changes in origin-based consumption taxes on Foreign's welfare.

In regards to $A_{t_{o}}$, the first right-hand-side term is again the terms-of-trade effect of the higher $t_{o}$ on the country's welfare. ${ }^{17}$ In the present framework, with origin-based consumption taxes, a higher $t_{o}\left(t_{o}^{*}\right)$ entails negative impact on Home's (Foreign's) welfare through the termsof- trade effect. Thus, origin-based consumption taxes entail a terms of trade motive for lower rather than higher consumption taxes for a country when goods are substitutes in consumption. A higher $t_{o}$ entails a positive (negative) employment effect, if the exported goods are non-labor (labor) intensive. The third term of the expression is the induced negative private consumption effect. The last term of the expression is the fiscal effect of the higher $t_{o}$ on the country's welfare. It indicates that for a given tax base, i.e., $\left(E_{q_{x}}+E_{q_{y}}\right)$, the higher origin-based consumption tax ensures higher tax revenue and level of public good, which in turn exerts a positive impact on welfare. The second component of the fiscal effect is the impact of the country's higher origin-based consumption tax on own welfare, due to changes in the government's tax base, and level of public good provision. The effect is negative, i.e., the higher $t_{o}$ lowers the tax base and level of $g$, thus it exerts a negative impact on the country's welfare. ${ }^{18}$

${ }^{16}$ By equations (9)-(10), $\left(1+\frac{d p_{x}}{d t_{o}}\right)=\frac{d q_{x}}{d t_{o}}=\frac{d q_{x}^{*}}{d t_{o}}=-\Delta^{-1} Z_{y} R_{p_{x} p_{x}}>0$ and $\left(1+\frac{d p_{y}^{*}}{d t_{o}^{*}}\right)=\frac{d q_{y}}{d t_{o}^{*}}=\frac{d q_{y}^{*}}{d t_{o}^{*}}=-\Delta^{-1} Z_{x} R_{p_{y}^{*} p_{y}^{*}}^{*}>0$.

${ }^{17}$ The complete expression for this term is $-\left[\left(E_{q_{x}}-R_{p_{x}}\right)\left(d p_{x} / d t_{o}\right)+E_{q_{y}}\left(d p_{y}^{*} / d t_{o}\right)\right]$, which due to the symmetry assumption reduces to the above term, see discussion of equations (11).

${ }^{18}$ Using equations (9) and (10), after some algebra, the second component of the fiscal effect can be written as $E_{g} t_{o} \Delta^{-1} R_{p_{x} p_{x}}\left[\left(E_{q_{x} q_{x}}+E_{q_{x}^{*} q_{x}^{*}}^{*}\right)\left(E_{q_{y} q_{y}}+E_{q_{y}^{*} q_{y}^{*}}^{*}\right)-\left(E_{q_{x} q_{y}}+E_{q_{x}^{*} q_{y}^{*}}^{*}\right)^{2}-R_{p_{y}^{*} p_{y}^{*}}^{*}\left(E_{q_{x} q_{x}}+E_{q_{x}^{*} q_{x}^{*}}^{*}\right)\right]$, which is negative. 
Observing the terms in $A_{t_{o}}$, similar arguments can be constructed for the term-of-trade and employment externalities of a higher $t_{o}^{*}$, the origin-based consumption tax by Foreign, on Home's welfare. In this case, however, $\left(\frac{d p_{x}}{d t_{o}^{*}}-\frac{d p_{y}^{*}}{d t_{o}^{*}}\right)$ is positive, implying a positive terms-oftrade externality on Home when Foreign raises its origin-based consumption tax and goods are substitutes in consumption. The second term of $\mathrm{A}_{t_{o}^{*}}$ indicates that a higher $t_{o}^{*}$ creates a positive employment externality if the exported good is non-labor (labor) intensive and goods are complements (substitutes) in consumption. In addition, the higher $t_{o}^{*}$ entails a negative private consumption externality, due to higher value of imports, i.e., $-E_{q_{v}} \cdot{ }^{19}$ The last term is the induced fiscal externality of the higher $t_{o}^{*}$, i.e., the effect of the higher $t_{o}^{*}$ on Home's welfare through changes in the country's tax base, thus level of public good provision. A higher $t_{o}^{*}$ by Foreign expands (contracts) Home's tax base, thus it raises (lowers) public good provision and welfare, if commodities $x$ and $y$ are substitutes (complements) in consumption.

Proposition 3: Consider two symmetric large open economies with unemployment. Origin-based taxes are levied on consumption of traded goods. Then, a higher origin-based consumption tax by either country:

(i) exerts a positive terms-of-trade externality,

(ii) entails a positive employment effect if the exported goods are non-labor, and a positive employment externality if the exported goods are non-labor (labor) intensive and are complements (substitutes) in consumption,

(iii) entails a positive (negative) fiscal externality if goods are substitutes (complements) in consumption.

Setting $E_{u}\left(d u / d t_{o}\right)=A_{t_{o}}=0$ and $E_{u^{*}}^{*}\left(d u^{*} / d t_{o}^{*}\right)=B_{t_{o}^{*}}=0$ in equations (14), we obtain the two countries' best-response functions which yield the Nash origin-based consumption tax rates $\left(t_{o}^{N}, t_{o}^{* N}\right)$. Thus, we obtain:

\footnotetext{
${ }^{19}$ We borrow this terminology from Moriconi and Sato (2009) for the exact same effect, but under constant terms of trade (producers' prices).
} 


$$
\begin{aligned}
& t_{o}^{N}=\Omega_{o}^{-1}\left[-E_{q_{y}}\left(E_{g}+\frac{d p_{y}^{*}}{d t_{o}}-\frac{d p_{x}}{d t_{o}}\right)+\bar{w} L_{p_{x}} \frac{d p_{x}}{d t_{0}}-\left(1+E_{g}\right) E_{q_{x}}\right] \\
& t_{o}^{* N}=\Omega_{o}^{*-1}\left[-E_{q_{x}^{*}}^{*}\left(E_{g^{*}}^{*}+\frac{d p_{y}^{*}}{d t_{o}^{*}}-\frac{d p_{x}}{d t_{o}^{*}}\right)+\bar{w}^{*} L_{p_{y}^{*}}^{*} \frac{d p_{y}^{*}}{d t_{o}^{*}}-\left(1+E_{g^{*}}^{*}\right) E_{q_{y}^{*}}^{*}\right]
\end{aligned}
$$

where, $\Omega_{o}=E_{g}\left[\left(E_{q_{x} q_{x}}+E_{q_{x}^{*} q_{x}^{*}}^{*}\right)\left(1+\frac{d p_{x}}{d t_{o}}\right)+\left(E_{q_{x} q_{y}}+E_{q_{x}^{*} q_{y}^{*}}^{*}\right) \frac{d p_{y}^{*}}{d t_{o}}\right]$ and $\Omega_{o}^{*}$, equivalently defined, are positive. The Nash equilibrium origin-based consumption taxes are positive if the exported goods are non-labor intensive, and there is no over-provision of the public good. ${ }^{20}$

To ascertain whether a country's Nash origin-based consumption tax $\left(t_{o}^{N}, t_{o}^{*^{N}}\right)$ is equally efficient as the cooperative one $\left(t_{o}^{c}, t_{o}^{* c}\right)$, we evaluate at Nash equilibrium the impact of the higher $\operatorname{tax}\left(t_{o}, t_{o}^{*}\right)$ on the countries joint welfare. The cooperative equilibrium, origin-based consumption taxes $\left(t_{o}^{c}, t_{o}^{* c}\right)$ are determined by setting $E_{u}\left(d u / d t_{o}\right)+E_{u^{*}}^{*}\left(d u^{*} / d t_{o}\right)=0$ for Home, and $E_{u}\left(d u / d t_{o}^{*}\right)+E_{u^{*}}^{*}\left(d u^{*} / d t_{o}^{*}\right)=0$ for Foreign. Evaluating these joint welfare functions at Nash equilibrium, once again it suffices to determine the sign of the $E_{u^{*}}^{*}\left(d u^{*} / d t_{o}\right)$ and $E_{u}\left(d u / d t_{o}^{*}\right)$ terms, since at Nash equilibrium $E_{u}\left(d u / d t_{o}\right)=E_{u^{*}}^{*}\left(d u^{*} / d t_{o}^{*}\right)=0$. Doing so, the effect of a higher origin-based Home consumption tax on Foreign's welfare, evaluated at Nash equilibrium values is:

20 With under-provision of the public good, $\left|E_{g}\right|>1$ and $\left(E_{g}+\frac{d p_{y}^{*}}{d t_{o}}-\frac{d p_{x}}{d t_{o}}\right)$ is negative, since by equations (9) and (10), $\left(-1+\frac{d p_{y}^{*}}{d t_{o}}-\frac{d p_{x}}{d t_{o}}\right)=\Delta^{-1}\left[Z_{y}-\left(E_{q_{y} q_{x}}+E_{q_{y}^{*} q_{x}^{*}}^{*}\right)\right] R_{p_{x} p_{x}}<0$.Then, provided that there is no over-provision of the public good and independently of the relationship of commodities in consumption, the sign of $t_{o}^{N}$ depends on the sign of the employment effect $\bar{w} L_{p_{x}} \frac{d p_{x}}{d t_{0}}$. 


$$
E_{u^{*}}^{*} \frac{d u^{*}}{d t_{o}}=\left.B_{t_{o}}\right|_{t_{o}^{* N}}=\{\underbrace{E_{q_{x}^{*}}^{*}\left(\frac{d p_{y}^{*}}{d t_{o}}-\frac{d p_{x}}{d t_{o}}\right)}_{\text {terms of trade externality }}+\underbrace{\bar{w}^{*} L_{p_{y}^{*}}^{*} \frac{d p_{y}^{*}}{d t_{o}}}_{\text {employment externality }}-\underbrace{E_{g^{*}}^{*} t_{o}^{* N} \Delta^{-1}\left(E_{q_{x} q_{y}}+E_{q_{x}^{*} q_{y}^{*}}^{*}\right) R_{p_{x} p_{x}} R_{p_{y}^{*} p_{y}^{*}}^{*}}_{\text {fiscal externality }} \underbrace{-E_{q_{x}^{*}}^{*}}_{\begin{array}{c}
\text { private consumption } \\
\text { externality }
\end{array}}\} .
$$

Note that by footnote 20 , the sign of the combined terms of trade and private consumption externalities is negative. Therefore, a higher origin-based consumption tax by Home entails on Foreign's welfare (i) a combined negative terms of trade and private consumption externalities, (ii) a negative employment externality if Foreign's exported good $y$ is non-labor intensive and commodities $x$ and $y$ are substitutes in consumption, (iii) a positive fiscal externality if commodities $x$ and $y$ are substitutes in consumption and $t_{o}^{* N}$ is positive. Then the sign of $\left(d u^{*} / d t_{o}\right)$ depends on the magnitude of these three effects. If $\left.B_{t_{o}}\right|_{t_{o}^{*}}>0$, then $t_{o}^{N}<t_{o}^{c}$, otherwise, if $\left.B_{t_{o}}\right|_{t_{o}^{*}}<0$, then $t_{o}^{N}>t_{o}^{c}$. The following Proposition summarizes the preceding discussion.

Proposition 4: Consider two symmetric large open economies with unemployment. Origin-based taxes are levied on the consumption of traded goods. Then, a country's Nash equilibrium originbased consumption tax:

(i) is positive if the exported goods are non-labor intensive and there is no over-provision of the public consumption good,

(ii) it is higher than its corresponding cooperative tax rate, if goods are substitutes in consumption, the exported goods are non-labor intensive, and the induced employment externality dominates the fiscal externality.

The case of small open economies is again reproduced by setting $d p_{x}=d p_{y}^{*}=0$ in equations (14). The modified equations (14) in conjunction with footnote 15 indicate that there is neither an employment effect locally, nor an induced employment externality. However, the standard fiscal externality and private consumption externality, e.g., Lockwood (2001) and Haufler and Pflüger (2007), remain. The following Corollary summarizes the results in this case.

Corollary 2: Consider two symmetric small open economies with unemployment. A country's Nash equilibrium origin-based consumption tax (i) is positive if there is no over-provision of the public good, and (ii) it may be higher or lower than its corresponding cooperative rate, depending on the relationship of commodities in consumption. 


\section{Relating the results to Moriconi and Sato (2009)}

In this section we highlight the differences in the results between our case of small open economies to that of Moriconi and Sato (2009). These differences arise due to the different modeling of employment/unemployment considered in the two studies.

In Moriconi and Sato (2009), unemployment is completely demand driven, in the sense that one extra (less) unit of consumption generates one extra (less) unit of output produced, and one less (extra) unit of unemployment. ${ }^{21}$ As a result, in their framework, with fixed producers' prices, a higher destination-based consumption tax always entails a negative local employment effect and a negative employment externality abroad. A higher origin-based consumption tax leads to a negative local employment effect, and it entails a positive (negative) employment externality if goods are substitutes (complements) in consumption (see their Proposition 1, p. 942). Moreover, Nash equilibrium destination-based consumption taxes are higher relative to the corresponding cooperative equilibrium tax rates, while the Nash origin-based consumption tax is higher (higher/lower) than its corresponding cooperative rate if the tax rate is positive and the two goods are complements (substitutes) in consumption (see their Proposition 2, p. 943).

Here, contrary to the Moriconi and Sato (2009) modeling, unemployment/employment is supply-side related. Then, when countries are small, i.e., constant producers' prices, changes in destination or origin-based consumption taxes affect consumers' prices but have no impact on producers' prices. As a result, contrary to the Moriconi and Sato (2009) study, changes in these tax rates do not entail either a local employment effect or an employment externality abroad. Moreover, again contrary to Moriconi and Sato (2009), in our case the Nash equilibrium destination-based consumption tax is always equally efficient to its cooperative equilibrium rate. The Nash origin-based consumption tax is higher (higher/lower) than its corresponding cooperative rate if the tax rate is positive and the two goods are complements (substitutes) in consumption. This result is $\mathrm{n}$ line with the corresponding result of Moriconi and Sato (2009).

21 In terms of their modeling employment in the two countries is respectively denoted by $L=X+X^{*}$ and $L^{*}=Y+Y^{*}$ (see their equations 11, p. 941). 


\section{Concluding Remarks}

In this paper, we construct a perfectly competitive general equilibrium model of two large and symmetric countries, each producing under prefect competition two goods and a public consumption good. Destination or origin-based taxes are levied on the consumption of goods. An institutional minimum wage leads to involuntary unemployment in both countries. Within this context, we derive the Nash equilibrium consumption taxes under the two taxation principles and compare them to their Pareto efficient rates. In particular, although neither the destination nor the origin principle leads to socially (Pareto) efficient outcomes, we demonstrate that under the origin principle terms of trade effects appear, while these effects are absent in the destinationbased commodity taxation. Also, the sign of the employment externality that commodity taxation causes may be positive or negative under the two principles.

Finally, it is shown that when countries are small, the Nash equilibrium destination-based consumption tax is equally efficient to its corresponding cooperative (Pareto efficient) rate. However, when countries are large, the Nash equilibrium destination-based consumption tax is lower than the corresponding cooperative equilibrium rate, if exported goods are non-labor intensive. The Nash equilibrium origin-based taxes, and regardless of whether countries are small or large, can be either higher or lower than the corresponding cooperative rates.

\section{Appendix}

\section{Commodity tax competition and producer prices}

Under the destination principle, total differentiation of equations (5) and (6) yields the following matrix system:

$$
\left[\begin{array}{cc}
Z_{x} & \left(E_{q_{x} q_{y}}+E_{q_{x}^{*} q_{y}^{*}}^{*}\right) \\
\left(E_{q_{y} q_{x}}+E_{q_{y}^{*} q_{x}^{*}}^{*}\right) & Z_{y}
\end{array}\right]\left[\begin{array}{l}
d p_{x} \\
d p_{y}^{*}
\end{array}\right]=\left[\begin{array}{c}
-\left(E_{q_{x} q_{x}}+E_{q_{x} q_{y}}\right) \\
-\left(E_{q_{y} q_{x}}+E_{q_{y} q_{y}}\right)
\end{array}\right] d t_{d}+\left[\begin{array}{c}
-\left(E_{q_{x}^{*} q_{x}^{*}}^{*}+E_{q_{x}^{*} q_{y}^{*}}^{*}\right) \\
-\left(E_{q_{y}^{*} q_{x}^{*}}^{*}+E_{q_{y}^{*} q_{y}^{*}}^{*}\right)
\end{array}\right] d t_{d}^{*} .
$$

Then, equations (7) and (8) in text emerge. Using equations (A.1), (7) and (8) in the text, the effect of changes in $t_{d}$ on $p_{x}$ and $p_{y}^{*}$ can be written as: 


$$
\begin{aligned}
\Delta \frac{d p_{x}}{d t_{d}} & =-\left(E_{q_{y} q_{y}}+E_{q_{y}^{*} q_{y}^{*}}^{*}\right)\left(E_{q_{x} q_{x}}+E_{q_{x} q_{y}}\right)+\left(E_{q_{y} q_{y}}+E_{q_{y} q_{x}}\right)\left(E_{q_{x} q_{y}}+E_{q_{x}^{*} q_{y}^{*}}^{*}\right) \\
& +R_{p_{y}^{*} p_{y}^{*}}^{*}\left(E_{q_{x} q_{x}}+E_{q_{x} q_{y}}\right), \\
\Delta \frac{d p_{y}^{*}}{d t_{d}} & =-\left(E_{q_{x} q_{x}}+E_{q_{x}^{*} q_{x}^{*}}^{*}\right)\left(E_{q_{y} q_{x}}+E_{q_{y} q_{y}}\right)+\left(E_{q_{x} q x}+E_{q_{x} q_{y}}\right)\left(E_{q_{y} q_{x}}+E_{q_{y}^{*} q_{x}^{*}}^{*}\right) \\
& +R_{p_{x} p_{x}}\left(E_{q_{y} q_{y}}+E_{q_{y} q_{x}}\right) .
\end{aligned}
$$

Assuming that (i) the two countries are symmetric, e.g., $E_{q_{x} q_{x}}=E_{q_{x}^{*} q_{x}^{*}}^{*}, E_{q_{x} q_{y}}=E_{q_{x}^{*} q_{y}^{*}}^{*}$, etc., and (ii) the direct substitution effect of the higher tax dominates its cross-substitution effect, i.e., for Home $\left|E_{q_{x} q_{x}}\right|>\left|E_{q_{x} q_{y}}\right|,\left|E_{q_{y} q_{y}}\right|>\left|E_{q_{y} q_{x}}\right|$, and for Foreign, $\left|E_{q_{x}^{*} q_{x}^{*}}^{*}\right|>\left|E_{q_{y}^{*} q_{x}^{*}}^{*}\right|$ and $\left|E_{q_{y}^{*} q_{y}^{*}}^{*}\right|>\left|E_{q_{x}^{*} q_{y}^{*}}^{*}\right|$. Then, the determinant of the right-hand-side matrix of the coefficients of the unknowns is $\Delta=Z_{x} Z_{y}-\left(E_{q_{x} q_{y}}+E_{q_{x}^{*} q_{y}^{*}}^{*}\right)\left(E_{q_{y} q_{x}}+E_{q_{y}^{*} q_{x}^{*}}^{*}\right)$ and is positive. Also, in $\left(d p_{x} / d t_{d}\right)<0$, and $\left(d p_{y}^{*} / d t_{d}\right)<0$. Similar methodology supports the rest of the signs, i.e., $\left(d p_{x} / d t_{d}^{*}\right)<0$ and $\left(d p_{y}^{*} / d t_{d}^{*}\right)<0$.

Under the origin principle, total differentiation of equations (5) and (6) yields the following matrix system:

$$
\left[\begin{array}{cc}
Z_{x} & \left(E_{q_{x} q_{y}}+E_{q_{x}^{*} q_{y}^{*}}^{*}\right) \\
\left(E_{q_{y} q_{x}}+E_{q_{y}^{*} q_{x}^{*}}^{*}\right) & Z_{y}
\end{array}\right]\left[\begin{array}{l}
d p_{x} \\
d p_{y}^{*}
\end{array}\right]=\left[\begin{array}{c}
-\left(E_{q_{x} q_{x}}+E_{q_{x}^{*} q_{x}^{*}}^{*}\right) \\
-\left(E_{q_{y} q_{x}}+E_{q_{y}^{*} q_{x}^{*}}^{*}\right)
\end{array}\right] d t_{o}+\left[\begin{array}{c}
-\left(E_{q_{x} q_{y}}+E_{q_{x}^{*} q_{y}^{*}}^{*}\right) \\
-\left(E_{q_{y} q_{y}}+E_{q_{y}^{*} q_{y}^{*}}^{*}\right)
\end{array}\right] d t_{o}^{*},
$$

From which equations (9) and (10) emerge. Using equations (A.3) and (9) in the text the effect of changes in $t_{o}$ on $p_{x}$ can be written as:

$$
\begin{aligned}
& \Delta \frac{d p_{x}}{d t_{o}}=-\left(E_{q_{y} q_{y}}+E_{q_{y}^{*} q_{y}^{*}}^{*}\right)\left(E_{q_{x} q_{x}}+E_{q_{x}^{*} q_{x}^{*}}^{*}\right)+\left(E_{q_{x} q_{y}}+E_{q_{x}^{*} q_{y}^{*}}^{*}\right)^{2}+R_{p_{y}^{*} p_{y}^{*}}^{*}\left(E_{q_{x} q_{x}}+E_{q_{x}^{*} q_{x}^{*}}^{*}\right), \\
& \Delta \frac{d p_{y}^{*}}{d t_{o}}=R_{p_{x} p_{x}}\left(E_{q_{y} q_{x}}+E_{q_{y}^{*} q_{x}^{*}}^{*}\right) .
\end{aligned}
$$


Following the argument for the sign of $d p_{x} / d t_{d}$ in equation (A.2), we can also conclude that $d p_{x} / d t_{o}<0$, and $d p_{y}^{*} / d t_{o}^{*}<0$, while the signs of $d p_{x} / d t_{o}^{*}$ and $d p_{y}^{*} / d t_{o}$ are ambiguous. Moreover, due to symmetry, e.g., $R_{p_{x} p_{x}}=R_{p_{y}^{*} p_{y}^{*}}^{*}$, we have:

$\left(\frac{d p_{x}}{d t_{o}}-\frac{d p_{y}^{*}}{d t_{o}}\right)=-\left(E_{q_{y} q_{y}}+E_{q_{y}^{*} q_{y}^{*}}^{*}\right)\left(E_{q_{x} q_{x}}+E_{q_{x}^{*} q_{x}^{*}}^{*}\right)+\left(E_{q_{x} q_{y}}+E_{q_{x}^{*} q_{y}^{*}}^{*}\right)^{2}+R_{p_{y}^{*} p_{y}^{*}}^{*}\left(E_{q_{x} q_{x}}+E_{q_{x}^{*} q_{x}^{*}}^{*}-E_{q_{y} q_{x}}-E_{q_{y}^{*} q_{x}^{*}}^{*}\right)$.

Given that the direct effect of a price change dominates its indirect one on compensated demands, the sign of the right-hand-side expression in equation (A.5) is negative regardless of the relationship of the two commodities in consumption.

\section{References}

Behrens, K., Hamilton, J.H., Ottaviano G.I.P. and Thisse, J-F., 2007. Commodity tax harmonization and the location of industry, Journal of International Economics 72, 271291.

Behrens, K., Hamilton, J.H., Ottaviano, G.I.P. and Thisse, J.-F., 2009. Commodity tax competition and industry location under the destination and the origin principle, Regional Science and Urban Economics 39, 422-433.

COM, 2011, Communication from the Commission to the European Parliament, the Council and Social Committee. On the Future of VAT Towards a Simpler, More Robust and Efficient VAT System Tailored to the Single Market. European Commission, December 2011.

COM, 2014, European Commission Press Release, October 2014. Retrieved July 2015: http://europa.eu/rapid/press-release_IP-14-1216_en.htm

Diamond P.A. and Mirrles, J.A., 1971, Optimal taxation and public production I-II, American Economic Review 61, 8-27; 261-78.

Dixit, A.K. and Norman, V., 1980, Theory of international trade, Cambridge University Press.

Emran, M.S., 2005, Revenue-increasing and welfare-enhancing reform of taxes on exports. Journal of Development Economics 77, 277-292.

Emran, M.S.,Stiglitz, J.E., 2005, On selective indirect tax reform in developing countries. Journal of Public Economics 89, 599-623.

Eurostat, 2014, Taxation trends in the European Union: Data from the EU Member States, Iceland and Norway, Eurostat Statistical Books. 
Falvey, R. and Kreickemeier, U., 2009, Tariff reforms with rigid wages, Economic Theory 41, 23-39.

Haufler, A., 1994, Unilateral tax reform under the restricted origin principle, European Journal of Political Economy 10, 511-527.

Haufler, A. and Pflüger, M., 2004. International commodity taxation under monopolistic competition, Journal of Public Economic Theory 6, 445-470.

Haufler, A., Schjelderup, G. and Stähler, F., 2005. Barriers to trade and imperfect competition: the choice of commodity tax base, International Tax Public Finance 12, 281-300.

Haufler, A. and Pflüger, M., 2007, International Oligopoly and the taxation of commerce with revenue-constrained governments, Economica 74, 451-473.

Kanbur, R. and Keen, M., 1993, Jeux sans frontiers: tax competition and tax coordination when countries differ in size, American Economic Review 63, 877-892.

Keen, M. and Lahiri, S., 1998, The comparison between destination and origin principles under imperfect competition, Journal of International Economics 45, 323-350.

Keen, M., and Wildasin, D. 2004, Pareto-efficient international taxation, American Economic Review 94, 259-75.

Kreickemeier, U., 2005, Unemployment and the welfare effects of trade policy, Canadian Journal of Economics 38, 194-210.

Lockwood, B., 2001, Tax competition and tax co-ordination under destination and origin principles: a synthesis, Journal of Public Economics 81, 279-319.

Lockwood, B., 1993. Commodity tax competition under destination and origin principles. Journal of Public Economics 52, 141-162.

Mintz, J. and Tulkens, H., 1986, Commodity tax competition between member states of a federation: equilibrium and efficiency, Journal of Public Economics 29, 133-172.

Moriconi, S. and Sato, Y., 2006, Commodity taxation in the presence of unemployment, CORE Discussion Papers 2006/69.

Moriconi, S. and Sato, Y., 2009, International Commodity Taxation in the presence of unemployment, Journal of Public Economics 93, 939-949.

Nam, C.W., Parsche, R., Schaden, B., 2001, Measurement of value added tax evasion in selected EU countries on the basis of national accounts data. ifo Studien 47, 127-144.

OECD, 2014, Consumption Tax Trends 2014. OECD Publishing. 